\title{
HUBUNGAN ANGKA KEJADIAN OMSK TERHADAP PHBS DI POLIKLINIK THT-KL RUMAH SAKIT PERTAMINA BINTANG AMIN KOTA BANDAR LAMPUNG
}

\author{
Muslim Kasim ${ }^{1}$, Selvia Anggreani ${ }^{2}$, Fatah Satya Wibawa ${ }^{3}$, Eunike Kusuma \\ Yanti $^{4}$
}

\author{
1'Departemen THT Rumah Sakit Pertamina Bintang Amin \\ ${ }^{2}$ Staf Pengajar Fakultas Kedokteran Universitas Malahayati \\ ${ }^{3}$ Departemen THT Rumah Sakit Pertamina Bintang Amin \\ ${ }^{4}$ Program Studi Kedokteran Fakultas Kedokteran Universitas Malahayati \\ Email: eunike.kusumayanti@yahoo.com
}

\section{ABSTRACT: RELATIONSHIP RELATIONSHIP OF CSO EVENTS TO PHBS IN THT- KL POLICLINIC PERTAMINA BINTANG AMIN HOSPITAL BANDAR LAMPUNG CITY}

Background: Chronic suppurative otitis media (CSOM) is an inflammation of middle ear and mastoid occurs more than 2 months, characterized by tympanic membrane perforation and the presence of fluid coming out of the ear canal. Clean and Healthy Living Behavior (PHBS) is the basis for health development to improve public health status. PHBS is a protection against the threat of diseases such as CSOM.

Method: This study is a quantitative study. The method is using medical records and questionnaires. Data analysis method Chi square test.

Result: The study was conducted at Pertamina Bintang Amin Hospital with a total of 54 respondents, 32 (59.3\%) male and 22 (40.7\%) female. The incidence of OMSK with good PHBS was 18 people or $33.3 \%$ of the total, which included 16 people or $88.9 \%$ of whom did not experience OMSK, while as many as 2 people or $11.1 \%$ experienced OMSK. Respondents with bad PHBS were 36 people or $66.7 \%$ of the total, which included 7 people or $19.4 \%$ did not experience OMSK, while 29 people or $80.6 \%$ experienced OMSK. Then, a bivariate analysis was performed and $p$ value was obtained $=0.001$. Thus, there was a significant relationship between OMSK and PHBS in the ENT-KL polyclinic at Bintang Amin Hospital, Bandar Lampung City.

Conclusion: There is a significant relationship between the incidence of CSOM and PHBS in the ENT-KL polyclinic at Bintang Amin Hospital, Bandar Lampung City.

Keywords: CSOM, PHBS, Ears, Nose, Throat.

\section{INTISARI: HUBUNGAN ANGKA KEJADIAN OMSK TERHADAP PHBS DI POLIKLINIK THT-KL RUMAH SAKIT PERTAMINA BINTANG AMIN KOTA BANDAR LAMPUNG}

Latar Belakang: Otitis media supuratif kronik (OMSK) merupakan suatu peradangan di telinga tengah dan bagian mastoid yang terjadi lebih dari 2 bulan ditandai dengan perforasi membran timpani dan adanya cairan yang keluar dari liang telinga. Perilaku Hidup Bersih dan Sehat (PHBS) adalah dasar pembangunan kesehatan untuk meningkatkan status kesehatan masyarakat. PHBS merupakan pelindung terjadinya ancaman penyakit seperti OMSK.

Metode Penelitian: Penelitian ini adalah penelitian kuantitatif. Cara pengumpulan dengan meggunakan rekam medis dan kuesioner. Metode analisis data Uji Chi square. 
Hasil: Penelitian dilakukan di Rumah Sakit Pertamina Bintang Amin dengan jumlah responden sebanyak 54 orang dengan jenis kelamin laki-laki sebanyak 32 $(59,3 \%)$ orang lebih banyak daripada jenis kelamin perempuan sebanyak 22 $(40,7 \%)$ orang. Angka kejadian OMSK dengan PHBS yang baik sebanyak 18 orang atau 33,3\% dari total keseluruhan yang mencakup 16 orang atau 88,9\% diantaranya tidak mengalami OMSK sedangkan sebanyak 2 orang atau $11,1 \%$ mengalami OMSK. Responden dengan PHBS yang buruk sebanyak 36 orang atau $66,7 \%$ dari total keseluruhan yang mencakup 7 orang atau 19,4\% tidak mengalami OMSK sedangkan sebanyak 29 orang atau $80,6 \%$ mengalami OMSK. Kemudian, dilakukan analisis bivariat dan didapatkan nilai $p=0,001$. Dengan demikian, terdapat hubungan bermakna antara OMSK dengan PHBS di poliklinik THT-KL Rumah Sakit Bintang Amin Kota Bandar Lampung.

Kesimpulan : Terdapat hubungan yang signifikan antara angka kejadian OMSK dengan PHBS di poliklinik THT-KL Rumah Sakit Bintang Amin Kota Bandar Lampung.

Kata Kunci: OMSK, PHBS, Telinga, Hidung, Tenggorokan

\section{PENDAHULUAN}

Otitis media supuratif kronik (OMSK) merupakan suatu peradangan di telinga tengah dan bagian mastoid yang terjadi lebih dari 2 bulan ditandai dengan perforasi membran timpani dan adanya cairan yang keluar dari liang telinga (Ahmed Z, Khan TZ dan Rahim DU, 2016). Perforasi membran timpani dapat ditemukan didaerah sentral, marginal atau atik.

Epidemiologi OMSK di seluruh dunia menurut WHO (2012) mencapai 65 sampai 330 juta orang dengan otorea dan $60 \%$ (39 sampai 200 juta orang) diantaranya mengalami gangguan pendengaran yang signifikan. Prevalensi OMSK di Inggris sebesar $0,9 \%$ terjadi pada anak-anak dan $0,5 \%$ pada orang dewasa memiliki OMSK. Tercatat WHO (2012), kejadian OMSK di Nepal terjadi pada usia < 10 tahun dengan persentase $34,8 \%$. Prevalensi OMSK di Indonesia berkisar 5,4 \% (semua umur). Prevalensi penurunan pendengaran pada dewasa akibat OMSK di Asia sebanyak 71 juta penduduk dengan penderita laki-laki lebih banyak 57,75 \% dibandingkan perempuan 42,25\% (WHO, 2012). Menurut Riset Kesehatan Dasar (Riskesdas) Kementrian Kesehatan
(Kemenkes) tahun 2013, prevalensi gangguan pendengaran akibat OMSK sebesar 2,6 \% dari seluruh total penduduk Indonesia dengan distribusi terbanyak pada usia lebih dari 45 tahun (Kemenkes RI, 2013). Menurut Sari (2018) data poliklinik THT RSUD. DR. H. Abdul Moeloek Bandar Lampung tahun 2017 menunjukan pasien OMSK merupakan 16,1 \% dari seluruh kunjungan pasien (Sari, 2018).

Perilaku Hidup Bersih dan Sehat (PHBS) adalah dasar pembangunan kesehatan untuk meningkatkan status kesehatan masyarakat. Kemenkes (2013) menyatakan bahwa rumah tangga di Indonesia yang mempraktekkan PHBS baru mencapai $55,6 \%$ sedangkan capaian ini masih jauh jika dibandingkan dengan targetnya yaitu sebesar $65 \%$. Angka ini masih terlampau jauh dengan target Rencana Strategis (Restra) Kemenkes tahun 2010 - 2014 yang menstandarisasi sebesar 70 \% rumah tangga sudah mempraktekkan PHBS pada tahun 2014 (Kemenkes, 2014).

Berdasarkan data Kemkes (2013) yang ada, OMSK merupakan salah satu penyakit yang dapat mengancam kehidupan seseorang. Sehingga diperlukan terapi yang 
sesuai untuk dapat mengatasinya dan supaya tidak menimbulkan komplikasi. Selain itu, pengobatan saja tidak cukup melainkan diperlukannya pencegahan agar dapat mengurangi kejadian OMSK dan komplikasinya (Ristin M, 2015). Oleh karena itu, peneliti ingin mengetahui apakah terdapat hubungan antara Perilaku Hidup Bersih dan Sehat (PHBS) terhadap kejadian Otitis Media Supuratif Kronik (OMSK) di Poliklinik THT-KL Rumah Sakit Pertamina Bintang Amin Kota Bandar Lampung.

\section{METODE PENELITIAN}

Penelitian ini adalah penelitian kuantitatif berupa analitik deskriptif observasional dengan pendekatan cross sectional, karena data penelitian berupa variable bebas (independent) dan terikat (dependent) dikumpulkan dalam waktu yang bersamaan (Notoatmodjo, 2012).

Penelitian dilakukan di Poliklinik THT-KL Rumah Sakit Bintang Amin Kota Bandar Lampung dan akan dilaksanakan pada bulan Juni 2020 sampai dengan selesai. Populasi dalam penelitian ini adalah seluruh pasien yang terdiagnosis OMSK dan bukan OMSK di poliklinik THT-KL Rumah Sakit Bintang Amin Kota Bandar Lampung pada tahun 2020, 2019, dan 2018 dengan sampel penelitian sebanyak 54 responden.

Data yang diperoleh dalam penelitian ini berupa data primer dan data sekunder. Data primer merupakan data yang diperoleh peneliti langsung dari sumber pertama langsung yaitu seluruh pasien yang mengalami OMSK dan tidak mengalami OMSK di Poliklinik THT-KL Rumah Sakit Bintang Amin Kota Bandar Lampung. Data sekunder merupakan data pasien OMSK dan tidak OMSK nya telah ada didalam rekam medik. Kuesioner sudah Tabel 1. Karakteristik Responden dilakukan uji validasi Kuesioner yang digunakan dalam penelitian telah melalui uji validitas dan reliabilitas dengan hasil akhir terdapat 12 pertanyaan yang dapat digunakan dalam penelitian dengan semua pertanyaan valid dan layak digunakan. Setelah mendapatkan item pertanyaan yang valid, diuji reliabilitasnya dengan menggunakan perangkat lunak dan didapatkan hasil nilai Cronbach's alpha yaitu 0,756. Nilai 0,756 . Pada penelitian ini terdapat uji etik dengan nomor surat: No.1089/EC/KEP-UNMAL/VIII/2020.

\section{HASIL PENELITIAN}

Penelitian mengenai hubungan perilaku hidup bersih dan sehat (PHBS) terhadap angka kejadian otitis media supuratif kronik (OMSK) di Poliklinik THT-KL Rumah Sakit Bintang Amin Kota Bandar Lampung sudah dilakukan selama bulan Juni 2020. Penelitian ini melibatkan 54 responden yang masuk didalam kriteria inklusi dan eklusi. Data diambil secara langsung dengan menggunakan kuesioner serta hasil pemeriksaan langsung terhadap pasien OMSK yang dilakukan oleh dokter spesialis THT (telinga, hidung dan tenggorokan) di poliklinik THT-KL Rumah Sakit Bintang Amin Kota Bandar Lampung.

\section{Analisis Univariat Gambaran Karakteristik Responden}

Berikut karakteristik responden berdasarkan jenis kelamin disajikan pada tabel di bawah ini. 


\begin{tabular}{lcc}
\hline Jenis & \multicolumn{2}{c}{ Total } \\
\cline { 2 - 3 } Kelamin & $\mathrm{N}$ & $\%$ \\
\hline & & \\
Laki-laki & 32 & 59,3 \\
Perempuan & 22 & 40,7
\end{tabular}

Berdasarkan tabel 1 didapatkan hasil bahwa jenis kelamin laki-laki dengan jumlah $32(59,3 \%)$ orang lebih banyak daripada jenis kelamin perempuan dengan jumlah $22(40,7 \%)$ orang.

Tabel 2. Jumlah Responden OMSK dan Tidak OMSK

\begin{tabular}{lcc}
\hline Jenis Kelamin & \multicolumn{2}{c}{ OMSK } \\
\cline { 2 - 3 } & Iya $(\%)$ & Tidak $(\%)$ \\
\hline \multirow{2}{*}{ Laki-laki } & $16(50)$ & $16(50)$ \\
Perempuan & $15(68,2)$ & $7(31,8)$
\end{tabular}

Berdasarkan tabel 2 didapatkan hasil bahwa jenis kelamin laki-laki dengan jumlah 32 orang yang mengalami OMSK sebanyak 16 (50\%) orang dan yang tidak mengalami OMSK sebanyak 16 (50 \%) sedangkan untuk yang

\section{Angka Kejadian OMSK}

Berikut angka kejadian OMSK di poliklinik Rumah Sakit Bintang Amin berjenis kelamin perempuan dengan jumlah 22 orang yang mangalami omsk sebanyak $15(55,6 \%)$ orang dan yang tidak mengalami omsk sebanyak $7(31,8 \%)$ orang.

Kota Bandar Lampung yang akan disajikan pada tabel 3.

Tabel 3. Angka kejadian OMSK

\begin{tabular}{lcc}
\hline Kejadian OMSK & \multicolumn{2}{c}{ Total } \\
\cline { 2 - 3 } & $\mathrm{N}$ & $\%$ \\
\hline & & \\
Ya & 31 & 57,4 \\
Tidak & 23 & 42,6
\end{tabular}

Berdasarkan tabel 3 didapatkan hasil bahwa yang mengalami OMSK sebanyak $31(57,4 \%)$ orang dan yang tidak mengalami OMSK sebanyak 23 $(42,6 \%)$ orang.

\section{Gambaran PHBS}


Berikut gambaran perilaku hidup bersih dan sehat (PHBS) penderita

OMSK dan tidak OMSK disajikan pada tabel 4.

Tabel 4. Gambaran PHBS

\begin{tabular}{lcc}
\hline Gambaran & \multicolumn{2}{c}{ Total } \\
\cline { 2 - 3 } PHBS & $\mathrm{N}$ & $\%$ \\
& & \\
\hline Baik & 18 & 33,3 \\
Buruk & 36 & 66,7
\end{tabular}

Berdasarkan tabel 4 didapatkan hasil bahwa yang memiliki perilaku hidup bersih dan sehat (PHBS) yang baik sebanyak $18(33,3 \%)$ orang dan yang

\section{Analisis Bivariat}

Data analisis menggunakan; uji chi square dikarenakan menggunakan tabel berukuran $2 \times 2$. Berikut hasil uji chi square hubungan perilaku hidup memiliki perilaku hidup bersih dan sehat (PHBS) buruk sebanyak $36(66,7$ $\%)$ orang.

bersih dan sehat (PHBS) terhadap angka kejadian otitis media supuratif kronik (OMSK) di poliklinik THT-KL Rumah Sakit Bintang Amin Kota.

Tabel 5. Hubungan Kejadian OMSK dengan PHBS

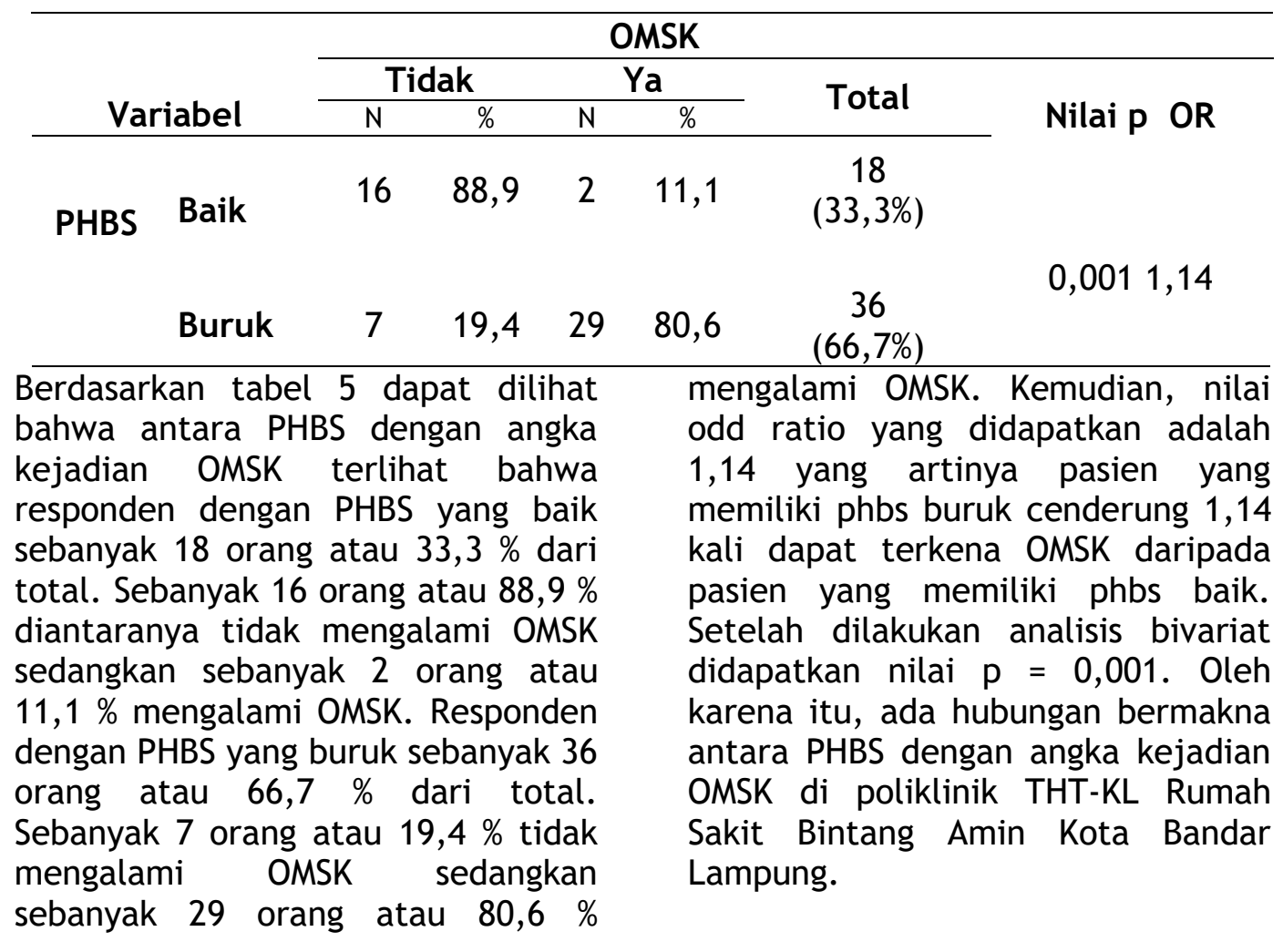


PEMBAHASAN

Analisis Univariat

Gambaran karakteristik responden

Pada penelitian ini didapatkan bahwa jumlah pasien OMSK berjenis kelamin laki-laki lebih banyak dibandingkan dengan perempuan. Berdasarkan tabel 1 didapatkan hasil bahwa jenis kelamin laki-laki dengan jumlah $32(59,3 \%)$ orang lebih banyak daripada jenis kelamin perempuan dengan jumlah $22(40,7 \%)$ orang. Hasil penelitian ini sesuai dengan penelitian yang dilakukan oleh Neogi $R$ et al (2011) di India, insidensi jenis kelamin terbanyak pada kasus OMSK adalah laki-laki (58,8 \%).

Penelitian yang dilakukan oleh Razooqi et al (2012) di Iraq, karakteristik sampel berdasarkan jenis kelamin menunjukan laki-laki $(52,8 \%)$ dan perempuan $(47,2 \%)$. Hal ini dapat diartikan bahwa laki-laki maupun perempuan

mempunyai risiko yang sama untuk menderita OMSK tipe benigna maupun maligna. Data yang diperoleh dari Riskesdas 2012 bahwa prevalensi OMSK pada laki-laki lebih tinggi daripada prevalensi OMSK pada perempuan (Kemenkes RI, 2011). Adapun terjadinya prevalensi lebih tinggi pada laki-laki banyak dikaitkan dengan faktor merokok. Suatu studi metaanalisis menunjukkan risiko otitis media yang meningkat yaitu sebesar $66 \%$ karena pengaruh paparan asap rokok (Kong dan Coates, 2009).

\section{Angka Kejadian OMSK}

Berdasarkan hasil penelitian angka kejadian OMSK dari tabel 3 didapatkan hasil bahwa yang mengalami OMSK sebanyak 31 (57,4 $\%)$ orang dan yang tidak mengalami OMSK sebanyak 23 (42,6\%) orang. Dari data yang ada pada rekam medis periode januari 2017 sampai dengan februari 2020 didapatkan responden sebanyak 54 orang, pada responden tersebut terdiri dari 31 orang yang mengalami OMSK dan 23 orang lainnya mengalami penyakit diluar OMSK yaitu Otitis Media Akut (OMA), Otitis Eksterna (OE), Otomikosis, Sinusitis dan Tinitus. Otitis media supuratif kronik terdiri dari 2 tipe yaitu OMSK tipe benigna (aman) dan tipe maligna (bahaya) (Bluestone, Klein, 2007).

\section{Gambaran PHBS}

Berdasarkan tabel 4 didapatkan hasil bahwa yang memiliki perilaku hidup bersih dan sehat (PHBS) yang baik sebanyak 18 (33,3\%) orang dan yang memiliki perilaku hidup bersih dan sehat (PHBS) buruk sebanyak 36 $(66,7 \%)$ orang. Adapun indikator PHBS yang digunakan dalam mengisi kuesioner yaitu kebiasaan mencuci tangan, kebiasaan merokok dan makan buah atau sayur setiap hari. Dari data yang kita ketahui bahwa banyak pasien OMSK yang memiliki PHBS yang buruk yaitu 29 orang atau $80,6 \%$. Hal tersebut bisa disebabkan karena kurangnya pengetahuan tentang kebiasaan cara mencuci tangan yang baik dan benar sehingga mudah terkontaminasi bakteri yang dapat menyebabkan penyakit seperti OMSK. Tangan terkena kuman sewaktu kita bersentuhan dengan bagian tubuh sendiri, tubuh orang lain, hewan atau permukaan yang tercemar. Walaupun kulit yang utuh akan melindungi tubuh dari infeksi langsung, kuman tersebut dapat masuk ke tubuh ketika tangan menyentuh mata, hidung, telinga atau mulut. Kebiasaan mencuci tangan dapat diterapkan setelah buang air besar, setelah menangani tinja anak, sebelum makan atau memberi makan anak dan sebelum menyiapkan makanan. (Anggrainy, 2010).

Selain itu, kurangnya pengetahuan pasien OMSK tentang bahayanya merokok yang dapat menyebabkan terjadinya OMSK. 
Suatu studi metaanalisis menunjukkan risiko otitis media yang meningkat yaitu sebesar $66 \%$ karena pengaruh paparan asap rokok (Kong dan Coates, 2009).

Paparan asap rokok berkontribusi meningkatkan risiko terjadinya otitis media kronik, asap rokok akan menyebabkan gangguan dari fungsi mukosiliar tuba eustasius. Namun dari penelitian ini tidak didapatkan hubungan yang signifikan antara paparan asap rokok dengan kekerapan terjadinya otorea pada OMSK (Zhang et al, 2014).

\section{Analisis Bivariat}

Berdasarkan tabel 5 dapat dilihat bahwa antara PHBS dengan angka kejadian OMSK terlihat bahwa responden dengan PHBS yang baik sebanyak 18 orang atau 33,3\% dari total. Sebanyak 16 orang atau $88,9 \%$ diantaranya tidak mengalami OMSK sedangkan sebanyak 2 orang atau $11,1 \%$ mengalami OMSK. Responden dengan PHBS yang buruk sebanyak 36 orang atau $66,7 \%$ dari total. Sebanyak 7 orang atau $19,4 \%$ tidak mengalami OMSK sedangkan sebanyak 29 orang atau 80,6\% mengalami OMSK. Setelah dilakukan analisis bivariat didapatkan nilai $\mathrm{p}=$ 0,001 . Oleh karena itu, ada hubungan bermakna antara PHBS dengan angka kejadian OMSK di poliklinik THT-KL Rumah Sakit Bintang Amin Kota Bandar Lampung.

Penelitian meta analisis yang telah dilakukan menunjukan bahwa alergi, riwayat infeksi saluran pernapasan akut (ISPA), riwayat otitis media akut (OMA), paparan asap rokok dan rendahnya status sosial adalah faktor-faktor risiko yang penting untuk OMSK (Zhang et al, 2014). OMSK sangat dipengaruhi oleh lingkungan dan perilaku diri sendiri, seperti: kebiasaan mencuci tangan yang kurang baik, mudah terkena polusi udara (asap rokok) atau perilaku merokok di dalam rumah dan nutrisi yang buruk yaitu kurangnya asupan makanan yang bergizi seperti makan buah dan sayur setiap hari. OMSK dipengaruhi atau ditimbulkan oleh tiga hal yaitu adanya kuman, keadaan daya tahan tubuh (status nutrisi, imunisasi) dan keadaan lingkungan (rumah yang kurang ventilasi, lembab, basah, dan kepadatan penghuni) (Soepardi dkk, 2007). Notoatmodjo (2012) PHBS dipengaruhi oleh perilaku seseorang, dan perilaku itu sendiri terbagi menjadi tiga aspek, yakni: pengetahuan, sikap dan praktik. PHBS seseorang merupakan salah satu faktor penting untuk mendukung peningkatan status kesehatan dirinya sendiri. Perilaku yang tidak sehat dapat dilihat dari kebiasaan merokok, kebiasaan mencuci tangan yang buruk dan kebiasaan kurangnya makan buah dan sayur setiap hari yang merupakan faktor risiko terjadinya OMSK (Adisasmito, 2007).

\section{KESIMPULAN}

Berdasarkan hasil penelitian mengenai hubungan kejadian OMSK terhadap PHBS di Poliklinik THT-KL Rumah Sakit Pertamina Bintang Amin didapatkan kesimpulan bahwa : Prevalensi responden yang mengalami OMSK sebanyak $31 \quad(57,4$ $\%)$ orang dan yang tidak mengalami OMSK sebanyak $23(42,6 \%)$ orang. Gambaran responden yang memiliki perilaku hidup bersih dan sehat (PHBS) yang baik sebanyak 18 (33,3\%) orang dan yang memiliki perilaku hidup bersih dan sehat (PHBS) buruk sebanyak $36(66,7 \%)$ orang. Terdapat hubungan bermakna antara PHBS dengan angka kejadian OMSK di poliklinik THT-KL Rumah Sakit Bintang Amin Kota Bandar Lampung dengan nilai $p=0,001$. Odd ratio yang didapatkan adalah 1,14 yang artinya pasien yang memiliki phbs buruk cenderung 1,14 kali dapat terkena OMSK. 


\section{SARAN}

Adapun saran yang dapat diberikan oleh peneliti berdasarkan hasil penelitian adalah sebagai berikut : Sebagai informasi untuk penderita OMSK agar selalu melakukan PHBS dengan cara baik dan benar. Saran untuk peneliti lain perlu dilakukan penelitian lebih lanjut untuk mencari faktor risiko terjadinya OMSK dan PHBS. Adanya sosialisasi mengenai pola PHBS serta indikator PHBS agar dapat terhindar dari OMSK.

\section{DAFTAR PUSTAKA}

Ahmed Z, Khan TZ, Rahim DU. (2016). Otogenic complications of otitis media: experience at tertiary care hospital. Pak J Surg. 32(1):49- 53.

Anggrainy R. (2010). Cuci tangan menggunakan sabun dalam program mendukung perilaku hidup bersih dan sehat. From http: / / www. perilakuhidupbers ih(PHBS).com. Diakses pada tanggal 12 Juli 2020.

Bluestone, C.D., Klein, J.O. (2007). Otitis media, atelektasis, and eustachian tube dysfunction. In Bluestone, Stool, Kenna eds. Pediatric otolaryngology. $3^{\text {rd }}$ ed. London: WB Saunders, Philaselphia, 388-582.

Dahlan MS. (2009). Besar sampel dan cara pengambilan sampel dalam penelitian kedokteran dan kesehatan. Jakarta: Salemba Medika.

Kementrian Kesehatan Republik Indonesia. (2011). Pedoman PHBS. Kemenkes RI, Jakarta.

Kementrian Kesehatan Republik Indonesia. (2013). Pedoman PHBS. Kemenkes RI, Jakarta.

Kementrian Kesehatan Republik Indonesia. (2014). Prevalensi OMSK. Kemenkes RI, Jakarta.

Kong K dan Coates H. (2009). History, definitions, risk factors and burden of otitis media. MJA. Australia. 191(9). p S39-S43.

Neogi R, Dan A, Maity K, Basak B, Basu D, Acharya $M$, et al. (2011). Clinico-epidemiological profile of chronic suppurative otitis media patients attending a tertiary care hospital. J Indian Med Assoc. 109(5):324-6.

Notoatmodjo S. (2012). Pendidikan dan perilaku kesehatan. Jakarta: PT. Rineka Cipta.

Razooqi, Salim, Khefi, Al-Kadhimiya. (2012). Sensorineural Hearing Loss in Chronic Suppurative Otitis Media. Iraqi J Med Sci. 10(1):1-5.

Riskesdas. (2012). Hasil riset kesehatan dasar tahun 2011. Jakarta. Kemenkes.

Sari. (2018). Hubungan Perilaku Hidup Bersih dan Sehat (PHBS) terhadap Angka Kejadian Otitis Media Supuratif Kronik (Omsk) di Poliklinik THT-KL RSUD Dr. H. Abdul Moeloek Bandar Lampung. Fakultas Kedokteran, Universitas Lampung [skripsi]. Bandar Lampung: Fakultas Kedokteran Unila.

Soepardi EA, Iskandar N, Bashiruddin J. (2007). Buku Ajar Ilmu Kesehatan Telinga, Hidung, Tenggorokan, Kepala \& Leher. Edisi VI. Jakarta : FK UI.

World Health Organization. (2012). Suppurative otitis media burden of illness and management options. Geneva, Switzerland: WHO.

Zhang Y, Min X, Jin Z, et al. (2014). Risk factors for chronic and recurrent otitis media - A meta Analysis. Plosone; 1: p. 1-7. 